\title{
PENGARUH STRES KERJA DAN LINGKUNGAN KERJA TERHADAP KINERJA KARYAWAN PADA PT.INDUSTRI KEMASAN SEMEN GRESIK (IKSG) JENU TUBAN
}

\author{
Moh.Heru Budi Santoso \\ Prodi Manajemen, Fakultas Ekonomi, Universitas Islam Lamongan \\ $J l$. Veteran No.53A Lamongan \\ Telp. ( 0322 ) 324706, Faks. ( 0322 ) 324706 \\ Herubudi@unisla.ac.id
}

\begin{abstract}
Abstrak
Kondisi perusahaan yang nyaman akan menunjang keberhasilan suatu perusahaan,hal ini ditunjukan oleh hasil penelitian yang ada bahwasanya kondisi lingkungan perusahaan yang ideal akan mengahsilkan output yang maksimal.Pada penelitian ini bertujuan untuk mengidentisifikasi pengaruh Stres kerja dan lingkungan kerja terhadap kinerja karyawan pada PT.industri kemasan semen gresik (IKSG) Jenu Tuban.apakah memiliki pengaruh secara parsial,simultan dan variabel mana yang lebih dominan. Jenis penelitian yang dilakukan kuantitatif dengan Metode penelitian uji Validitas, Reabilitas, Regresi linier berganda, korelasi berganda, koefisien determinasi, uji t dan uji F.Hasil pengujian validitas diperoleh $\mathrm{X}_{1.1}=0,692, \mathrm{X}_{1.2}=0,758, \mathrm{X}_{1.3}=0,790$, . $\mathrm{r}_{\text {hitumg }} \mathrm{X}_{2.1}=0,744, \mathrm{X}_{2.2}$ $=0,759, X_{2.3}=0,622$. $r_{\text {hitung }} Y_{1.1}=0,730, Y_{1.2}=0,615 \quad Y_{1.3}=0,508$. dengan $t$ tabel 0,2579.sedangkan uji reabilitas $X_{1}=0,770 . r_{\text {hitumg }} X_{2}=0,752 \quad r_{\text {hitung }} Y=0,585$ lebih besar dari standart reliabilitas $\mathrm{x} 1=0,758 \quad \mathrm{x} 2=0,720 \quad \mathrm{y}=0,582$ dengan tingkat signifikasi $\alpha=5 \%$ untuk uji regresi $\mathrm{Y}=6.249+0,225 \mathrm{X}_{1}+0,305 \mathrm{X}_{2}$. Uji korleasi dipeoleh $0,429 \times 1$ dan $\mathrm{x} 2$ 0,529.uji determinasi diperoleh $0,668(66,8$ $\%$ ).uji $\mathrm{t}_{\text {Hitung }}\left(\mathrm{X}_{1}\right)=3,621$ dan $\mathrm{t}_{\text {Hitung }}\left(\mathrm{X}_{2}\right)=4,771$ dengan $\mathrm{t}_{\text {Tabel }}=2,011$.dan uji $\mathrm{F}$ diperoleh $\mathrm{F}_{\text {Hitung }}=19,347>\mathrm{F}_{\text {Tabel }}=3,16$. Dari hasil diatas dapat disimpulkan data tersebut valid,reabel ,dan terdapat hubungan secara parsial dan simultan,dan variabel yang dominan adalah kompensasi. sebagai masukan perusahaan hendaklah memperhatikan kondisi lingkungan agar tetap ideal dan juga kondisi psikologi karyawan agar tetap dapat bekerja secara optimal
\end{abstract}

Kata kunci : Stress kerja ,Lingkungan Kerja dan Kinerja karyawan.

\section{PENDAHULUAN}

Manajemen sumber daya manusia adalah bidang manajemen yang khusus mempelajari hubungan dan peranan manusia dalam organisasi perusahaan. Unsur manajemen sumber daya manusia adalah manusia yang merupakan tenaga kerja pada perusahaan (Hasibuan, 2014:9).

Tenaga Kerja manusia pada dasarnya dibedakan atas pengusaha, 
karyawan dan pemimpin, Tenaga kerja merupakan salah satu aset yang sangat penting. Manusia yang merupakan tenaga kerja bagi perusahaan kadang kala sering diabaikan sebagai aset yang berharga. Tak jarang, perusahaan hanya mengganggap bahwa tenaga kerja (karyawan) sebagai beban yang harus selalu ditekan untuk mengurangi biaya dalam produksi.

Menurut Soedarmayanti (2011:21) Lingkungan kerja adalah seluruh alat perkakas dan bahan yang dihadapi dilingkungan sekitarnya dimana seorang bekerja, metode bekerjannya, serta pengaturan kerjannya baik sebagai perseorangan maupun kelompok.

Stres pekerjaan dapat diartikan sebagai tekanan yang dirasakan karyawan karena tugas-tugas pekerjaan tidak dapat mereka penuhi. Artinya, stres muncul saat karyawan tidak mampu memenuhi apa yang menjadi tuntutan-tuntutan pekerjaan.

Dari kenyataan tersebut dapat diindikasikan bahwa stress kerja dapat terjadi karena adanya faktorfaktor dari dalam diri seseorang maupun lingkungan diluar diri seseorang. Faktor-faktor yang mempengaruhi kinerja karyawan dapat berasal dari tiga faktor, Faktor individu yang terdiri dari kemampuan dan keahilan, latar belakang, dan demografi.Faktor psikologis yang terdiri dari persepsi, attitude, pembelajaran dan motivasi. Serta Faktor organisasi yang terdiri dari Sumber daya, kepemimpinan, penghargaan, Struktur dan job design.

Kinerja karyawan merupakan suatu tindakan yang dilakukan karyawan dalam melaksanakan pekerjaan yang diberikan perusahaan (Handoko, 2014:135). Setiap perusahaan selalu mengharapkan karyawannya mempunyai prestasi, karena dengan memiliki karyawan yang berprestasi akan memberikan sumbangan yang optimal bagi perusahaan. Selain itu, dengan memiliki karyawan yang berprestasi perusahaan dapat meningkatkan kinerja perusahaanya.

$$
\text { Seringkali perusahaan }
$$
menghadapi masalah mengenai sumber daya manusianya. Masalah sumber daya manusia menjadi tantangan tersendiri bagi manajemen karena keberhasilan manajemen dan yang lain itu tergantung pada kualitas 
sumber daya manusianya. Apabila individu dalam perusahaan yaitu SDM-nya dapat berjalan efektif maka perusahaan tetap berjalan efektif. Dengan kata lain kelangsungan suatu perusahaan itu ditentukan oleh kinerja karyawannya.

Berdasarkan latar belakang dan permasalahan yang muncul diatas maka penelitian ini bertujuan untuk mengetahui:

1. Stres kerja dan Lingkungan kerja berpengaruh secara parsial terhadap Kinerja karyawan pada PT.Industri Kemasan Semen Grsik (Iksg) Jenu Tuban.

2. Stres kerja dan Lingkungan kerja berpengaruh secara simultan terhadap Kinerja karyawan pada PT.Industri Kemasan Semen Gresik (Iksg) Jenu Tuban.

3. Variabel manakah Stres kerja dan Llingkungan kerja yang paling dominan berpengaruh terhadap Kinerja karyawan PT.Industri Kemasan Semen Gresik (Iksg) Jenu Tuban.

Mangkunegara (2012: 28) ia mengatakan bahwa stres kerja adalah perasaan yang menekan atau merasa tertekan yang dialami karyawan dalam menghadapi pekerjaan. Stres kerja ini tampak dari symptom antara lain emosi tidak stabil, perasaan tidak tenang, suka menyendiri, sulit tidur, merokok yang berlebihan, tidak bias rileks, cemas, tegang, gugup, tekanan darah meningkat dan mengalami gangguan pencernaan.

Dari uraian diatas dapat disimpulkan bahwa terjadinya stres kerja itu dikarenakan adanya ketidakseimbangan antara karakteristik kepribadian karyawan dengan karakteristik aspek-aspek yang ada dalam pekerjaan karyawan yang tak jarang karyawan mengalami ketidakstabilan daya tahan tubuh, dalam hal ini dapat mempengaruhi daya tahan stres seorang karyawan.

\section{KAJIAN PUSTAKA}

Quick dalam Rivai (2010:308) mengategorikan jenis stres menjadi dua, yaitu :

1) Eutstress, yaitu hasil dari respons terhadap stres yang bersifat sehat, positif, dan konstruktif (bersifat membangun). Menurut Sopiah (20013:85) Eustress ini merupakan pengalaman stres yang tidak berlebihan, cukup untuk menggerakkan dan 
memotivasi orang agar dapat mencapai tujuan, mengubah lingkungan mereka dan $\mathrm{Hal}$ tersebut termasuk kesejahteraan individu, fleksibilitas, kemampuan adaptasi, dan tingkat performance yang tinggi.

2) Distress, yaitu hasil dari respons terhadap stres yang bersifat tidak sehat, negatif, dan destruktif (bersifat merusak). Hal tersebut termasuk konsekuensi individu dan juga organisasi yakni derajat penyimpangan fisik, psikis, dan perilaku dari fungsi yang sehat.

Menurut Carey Cooper dalam Jacinta F. Rini (2012:56) Indikatorindikator stress kerja adalah sebagai berikut :

1. Kondisi pekerjaan

Kondisi pekerjaan/ Lingkungan kerja yang buruk dapat menyebabkan karyawan mudah jatuh sakit, mudah stress, sulit berkonsentrasi, dan menurunnya produktivitas kerja.

2. Konflik peran

Dalam sebuah penelitian mengenai stress kerja, ditemukan fakta bahwa perusahaan yang sangat besar, atau yang kurang memiliki struktur yang jelas, akan menimbulkan konflik peran.

Mereka stress karena

3. Pengembangan karir

Stress kerja dapat timbul jika seseorang karyawan tidak merasa aman akan pekerjaannya.

4. Struktur organisasi

Apabila bentuk atau struktur organisasi kurang jelas dan terjadi dalam jangka waktu yang cukup lama, maka hal tersebut dapat menjadi sumber stress.

Lingkungan adalah segala hal yang terkait dengan operasional perusahaan dan bagaimana kegiatan operasional tersebut dapat berjalan, Trisnawati (2015:62). Lingkungan kerja yang baik akan sangat mempengaruhi tingkat produktivitas karyawan hal ini dapat dilihat dari peningkatan teknologi dan cara produksi, sarana dan peralatan produksi yang digunakan, tingkat keselamatan dan kesehatan kerja serta suasana lingkungan kerja itu sendiri.

Menurut Soedarmayanti (2012:159) indikator- indikator lingkungan kerja adalah sebagai berikut: 
a. Suasana kerja

Setiap karyawan selalu menginginkan suasan kerja yang menyenangkan, suasana kerja yang nyaman itu meliputi cahaya yang jelas, suara yang tidak bising dan tenang, keamanan di dlam bekerja.

b. Hubungan dengan rekan kerja

Hal ini dimaksudkan hubungan dengan rekan kerja harmonis dan tanpa ada saling intrik diantara sesama rekan kerja. Salah satu faktor yang dapat mempengaruhi karyawan tetap tinggal dalam suatu organisasi adalah adanya hubungan yang harminis diantra rekan kerja.

c. Tersedianya fasilitas kerja

Hal ini dimaksudakan bahwa peralatan yang digunakan untuk mendukung kelancaran kerj lengkap/ mutahir. Tersedianya fasilitas kerja yang lengkap, walaupun tidak baru merupakan salah satu penunjang proses kelancaran dalam bekerja.

Handoko

(2014:

mendefinisikan kinerja sebagai proses dimana organisasi mengevaluasi atau menilai prestasi kerja karyawan. Kinerja menurut Anwar Prabu Mangkunegara (2012:67) "Kinerja (prestasi kerja) adalah hasil kerja secara kualitas dan kuantitas yang dicapai oleh seseorang pegawai dalam melaksanakan tugasnya sesuai dengan tanggung jawab yang diberikan kepadanya".

Dari berbagai pengertian tentang kinerja diatas dapat disimpulkan bahwa kinerja adalah hasil atau taraf kesuksesan yang dicapai seseorang dalam bidang pekerjaannya menurut kriteria tertentu dan dievaluasi oleh orangorang tertentu terutama atasan pegawai yang bersangkutan. Dari definisi-definisi diatas dapat diketahui bahwa unsur-unsur yang terdapat dalam kinerja terdiri dari :

1. Hasil-hasil fungsi pekerjaan

2. Faktor-faktor yang berpengaruh terhadap prestasi kerja karyawan seperti : motivasi, kecakpan, persepsi perasaan dan tugas dan lain sebagainya.

3. Pencapain tujuan organisasi

4. Periode waktu tertentu

Sedangkan menurut Simamora yang dikutip oleh A.A Anwar Prabu Mangkunegara (2013:14), kinerja 
(performance) dipengaruhi oleh 3 faktor yaitu :

1. Faktor individu: kemampuan dan keahilan, latar belakang, dan demografi.

2. Faktor psikologis: persepsi, attitude, pembelajaran dan motivasi

3. Faktor organisasi : Sumber daya, kepemimpinan, penghargaan,Struktur dan job design.

\section{METODE PENELITIAN}

Jenis penelitian yang digunakan adalah penelitian Kuantitatif. Kuantitatif merupakan teknik pengumpulan data yang mnggunakan angka dalam mengumpulkan data, sehingga penggambaranya banyak menggunakan angka-angka. (Sugiyono,2013:43).

Populasi adalah keseluruhan data yang menjadi perhatian kita dalam suatu ruang lingkup dan waktu yang kita tentukan (Margono, 2013:118). Populasi dalam penellitian ini adalah karyawan PT.Industri Kemasan Semen Gresik (IKSG) Kecamatan Jenu Tuban Jawa Timur pada bidang produksi. Jumlah seluruh karyawan adalah
500.Sedangkan untuk perhitungan sampel dilakukan dengan menggunakan rumus Slovin dengan asumsi bahwa populasi tersebut bedistribusi normal, maka perhitungannya sebagai berikut (Umar, 2011:78) dengan jumlah sampel 51 responden.

Sumber data pada penelitian ini berasal dari dat primer dan skunder,dimana diperoleh dari penyebaran angket kuesionare point skala likert.varibel pada penelitian ini $\mathrm{X}_{1}$ (stres kerja) (Zaki Baridwan,2012:124) Indikatorindikator stres kerja sebagai berikut:

1. Kondisi pekerjaan

2. Konflik peran

3. Pngembangan karir

4. Struktur organisasi

Dan variabel $\mathrm{X}_{2}$ (Lingkungan kerja) (Sugiono, 2013:3) Indikatorindikator lingkungan kerja sebagai berikut:

1. Suasana kerja

2. Hubungan dengan rekan kerja

3. Tersedianya fasilitas kerja Sedangkan variabel Y ( Kinerja) . (Bambang Riyanto, 2010:35) Indikator-indikator kinerja karyawan sebagai berikut:

1. Kesetiaan 
2. Prestasi kerja

3. Kedisiplinan

4. Kerjasama

5. Tanggung jawab

Untuk metode analisis data digunakan beberapa ,metode penelitian diantaranya uji validitas dan reabilitas,uji regresi berganda,uji koefisien determinasi,uji t dan uji F.

\section{HASIL DAN PEMBAHASAN}

Responden pada sampel data penelitian ini sebanyak 51 responden yang merupakan karyawan tetap PT Industri kemasan semen Gresik (IKSG). mengenai responden yang menjadi sampel penelitian sesuai dengan jenis kelamin responden adalah sebagai berikut :

Tabel 1. responden

berdasarkan jenis kelamin

\begin{tabular}{|l|c|c|}
\hline $\begin{array}{l}\text { Jenis } \\
\text { kelamin }\end{array}$ & $\begin{array}{c}\text { Jumlah } \\
\text { Responden } \\
\text { (Orang) }\end{array}$ & Persentase \\
\hline Laki - laki & 39 & $76 \%$ \\
\hline Perempuan & 12 & $24 \%$ \\
\hline Jumlah & 51 & $100 \%$ \\
\hline
\end{tabular}

Sumber : Data primer (Diolah), 2019
Tabel 2.

Responden berdasarkan usia

\begin{tabular}{|l|c|c|}
\hline & $\begin{array}{l}\text { Jumlah } \\
\text { Karyawan } \\
\text { (Orang) }\end{array}$ & Presentase \\
\hline $\begin{array}{l}20-25 \\
\text { tahun }\end{array}$ & 14 & $27 \%$ \\
\hline $\begin{array}{l}25-30 \\
\text { tahun }\end{array}$ & 18 & $35 \%$ \\
\hline $\begin{array}{l}31-35 \\
\text { tahun }\end{array}$ & 10 & $20 \%$ \\
\hline $\begin{array}{l}36-40 \\
\text { tahun }\end{array}$ & 6 & $12 \%$ \\
\hline $\begin{array}{l}41-45 \\
\text { tahun }\end{array}$ & 3 & $6 \%$ \\
\hline Jumlah & 51 & $100 \%$ \\
\hline
\end{tabular}

SumberData Primer (Diolah), 2019

Tabel 3. Responden berdasarkan pendidikan

\begin{tabular}{|l|c|c|}
\hline Pendidikan & $\begin{array}{c}\text { Jumlah } \\
\text { Responden } \\
\text { (Orang) }\end{array}$ & Persentase \\
\hline $\begin{array}{l}\text { SMA } \\
\text { sederajat }\end{array}$ & 26 & $50 \%$ \\
\hline D1- D3 & 12 & $24 \%$ \\
\hline S1 & 9 & $18 \%$ \\
\hline Lebih dari & 4 & $8 \%$ \\
S1 & 51 & $100 \%$ \\
\hline Jumlah &
\end{tabular}

Sumber : Data primer (Diolah), 2019

Hasil pengujian validitas diperoleh nilai $\mathrm{r}_{\text {hitung }} \mathrm{X}_{1.1}=0,692, \mathrm{X}_{1.2}$ $=0,758, X_{1.3}=0,790, . r_{\text {hitumg }} X_{2.1}=$ $0,744, \quad X_{2.2}=0,759, X_{2.3}=0,622$. $\mathrm{r}_{\text {hitung }} \mathrm{Y}_{1.1}=0,730, \mathrm{Y}_{1.2}=0,615 \quad \mathrm{Y}_{1.3}=$ 0,508.Berdasarkan uji validitas untuk ketiga variabel bebas (X) dan variabel terikat (Y) diatas diperoleh $\mathrm{r}$ hitung > r tabel. $(0,2579)$,Sehingga 
keseluruhan indicator dari dua variabel tersebut dinyatakan valid.

Untuk uji reliabilitas dengan SPSS metode Alpha Cronbackh's diperoleh koefisien alpha pada variabel bebas Stres kerja $\mathrm{X}_{1 .}=0,770$. $\mathrm{r}_{\text {hitumg }} \mathrm{X}_{2 .}=0,752 \quad \mathrm{r}_{\text {hitung }} \mathrm{Y}=0,585$ lebih besar dari standart reliabilitas $\mathrm{x} 1=0,758 \quad \mathrm{x} 2=0,720 \quad \mathrm{y}=0,582$ dengan tingkat signifikasi $\alpha=5 \%$ sehingga dapatdisimpulkan bahwa instrument dalam variabel bebas dan terikat adalah reliabel.

Tabel 4. Uji regresi

\begin{tabular}{|c|c|c|c|}
\hline & \multicolumn{2}{|c|}{$\begin{array}{c}\text { Unstandardiz } \\
\text { ed } \\
\text { Coefficients }\end{array}$} & $\begin{array}{c}\text { Standar } \\
\text { dized } \\
\text { Coeffic } \\
\text { ients }\end{array}$ \\
\cline { 2 - 4 } Model & B & $\begin{array}{c}\text { Std. } \\
\text { Error }\end{array}$ & Beta \\
\hline $\begin{array}{l}\text { 1 Constant) } \\
\text { X1(stress } \\
\text { kerja) } \\
\text { X2(lingkun } \\
\text { gan kerja) }\end{array}$ & .249 & 1.044 & .305 \\
\hline
\end{tabular}

Dari tabel pengujian regresi diatas, pada kolom B diperoleh konstanta $\mathrm{a}=6.249, \mathrm{~b}_{1}=0,225, \mathrm{~b}_{2}=$ 0,305 , sehingga persamaan regresi gandanya adalah sebagai berikut: Y $=6.249+0,225 \mathrm{X}_{1}+0,305 \mathrm{X}_{2}$. Dimana Y adalah Peningkatan kinerja , $\mathrm{X}_{1}$ adalah Stres kerja, $\mathrm{X}_{2}$ adalah Lingkungan kerja.dan dari nilai koefisien regresi diatas dapat dilihat nilai tertingi pada variabel Lingkungan kerja,sehingga variabel yang tersebut lebih dominan mempengaruhi Kinerja.

Tabel 5. Koefisien diterminasi

\begin{tabular}{|l|l|r|r|}
\hline & & & \\
Mode & & & \\
1 & $\mathrm{R}$ & R Square & $\begin{array}{l}\text { Adjusted } \\
\text { R Square }\end{array}$ \\
\hline 1 & $.668^{\mathrm{a}}$ & .447 & .424 \\
\hline
\end{tabular}

Berdasarkan hasil perhitungan uji koefisien determinasi pada tabel di atas di peroleh angka $\mathrm{R}^{2}$ (R Square) sebesar 0,447 yang berarti 44,7\%. Hal ini menunjukkan bahwa persentase sumbangan pengaruh variabel independen (Stres kerja dan Lingkungan kerja) terhadap variabel dependen (Peningkatan Kinerja ) atau variasi variabel independen (Stres kerja, Lingkungan kerja) mampu menjelaskan sebesar $44,7 \%$ variabel dependen(Peningkatan Kinerja ). Sedangkan sisanya sebesar $55,3 \%$ ditentukan oleh variabel lain diluar variabel penelitian. 
Tabel 6. UJI T

\begin{tabular}{|c|c|c|c|c|}
\hline \multirow[b]{2}{*}{ Model } & \multicolumn{2}{|c|}{$\begin{array}{l}\text { Unstandardize } \\
\text { d Coefficients }\end{array}$} & \multirow[b]{2}{*}{$\mathrm{t}$} & \multirow[b]{2}{*}{ Sig. } \\
\hline & B & $\begin{array}{l}\text { Std. } \\
\text { Error }\end{array}$ & & \\
\hline 1 (Constant & $\begin{array}{r}6.24 \\
9\end{array}$ & 1.044 & 5.987 & .000 \\
\hline $\mathrm{X} 1$ & .225 & .069 & 3.261 & .002 \\
\hline $\mathrm{X} 2$ & .305 & .064 & 4.771 & .000 \\
\hline
\end{tabular}

Berdasarkan hasil uji t parsial yaitu Stres kerja $\left(\mathrm{X}_{1}\right)$, Lingkungan kerja $\left(\mathrm{X}_{2}\right)$, berpengaruh signifikan terhadap Peningkatan Kinerja Tenaga Kerja (Y), pada PT Industri kemasan semen Gresik (IKSG). Dari hasil uji t parsial diperoleh $\mathrm{t}_{\text {Hitung }}\left(\mathrm{X}_{1}\right)$ $=3,621>\mathrm{t}_{\text {Tabel }}=2,011, \mathrm{t}_{\text {Hitung }}\left(\mathrm{X}_{2}\right)=$ $4,771>\mathrm{t}_{\text {Tabel }}=2,011,$. Sehingga $\mathrm{H}_{\mathrm{O}}$ ditolak dan $\mathrm{H}_{\mathrm{a}}$ ditrerima, yang artinya dari kedua variabel (X) mempunyai pengaruh yang signifikan secara parsial terhadap variabel Peningkatan Kinerja Tenaga Kerja (Y) pada PT Industri kemasan semen Gresik (IKSG).

Tabel 7. Uji F

\begin{tabular}{|l|r|c|c|}
\hline Model & df & F & Sig. \\
\hline 1 Regressi & 2 & 19.374 & $.000^{\mathrm{a}}$ \\
on & & & \\
Residual & 48 & & \\
Total & 50 & & \\
\hline
\end{tabular}

Berdasarkan uji $F$ simultan diperoleh Stres kerja $\left(\mathrm{X}_{1}\right)$, Lingkungan kerja $\left(\mathrm{X}_{2}\right)$, berpengaruh simultansignifikan secara. Hal ini dibuktikan dari hasil $\mathrm{F}_{\text {Hitung }}=19,347$ $>\mathrm{F}_{\text {Tabel }}=3,16$ sehinga $\mathrm{Ho}_{\mathrm{O}}$ ditolak dan $\mathrm{H}_{\mathrm{a}}$ ditrima, yang artinya variabel Stres kerja $\left(\mathrm{X}_{1}\right)$, Lingkungan $\operatorname{kerja}\left(\mathrm{X}_{2}\right)$, mempunyai pengaruh yang signifikan secara simultan terhadap Peningkatan Kinerja Tenaga Kerja (Y) pada PT Industri kemasan semen Gresik (IKSG).

\section{KESIMPULAN}

Berdasarkan hasil penelitian yang dilakukan maka dapat disimpulkan bahwa : Adanya pengaruh secara parsial antara variabel Stres kerja $\left(\mathrm{X}_{1}\right)$, Lingkungan kerja $\left(\mathrm{X}_{2}\right)$, terhadap Peningkatan Kinerja Tenaga Kerja (Y) pada PT Industri kemasan semen Gresik (IKSG)

Variabel Stres kerja $\left(\mathrm{X}_{1}\right)$, Lingkungan kerja $\left(\mathrm{X}_{2}\right)$, mempunyai pengaruh yang signifikan secara simultan terhadap Peningkatan Kinerja Tenaga Kerja (Y) pada PT Industri kemasan semen Gresik (IKSG).

Variabel yang dominan mempengaruhi kinerja karyawan (Y) 
pada PT Industri kemasan semen Gresik (IKSG) adalah variabel ), Lingkungan kerja $\left(\mathrm{X}_{2}\right)$.

\section{DAFTAR PUSTAKA}

Anitawidanti, hafni. 2010. Analisis Hubungan Antara stres kerja dengan kepuasan Kerja Karyawan Berdasrkan Gender. Skripsi tidak diterbitkan. Semarang :Fakultas Ekonomi Universitas Diponegoro

Arikunto, Suharsimi. 2013. Manajemen Penelitian, Jakarta : Rineke Cipta

Handoko, T. H. 2014. Manajemen Personalia dan Sumber daya Manusia. Yogyakarta: BPFE

Handoko, Hani, Manajemen Personalia Dan Sumber Daya Manusia, Edisi Kedua, Penerbit BPFE_UGM, Yogyakarta, Halaman 69.

Hasibuan, S.P. Malayu. 2013. Manajemen Sumber Daya Manusia. Edisi Revisi. Jakarta: Bumi Aksara.

Henny, 2012. Hubungan Setres Kerja dengan kepuasan kerja karyawan bagian Customer care pada PT.Telekomunikasi Indonesia Tbk Bekasi. Skripsi tidak diterbitkan. Bogor:Jurusan Manajemen Fakultas Ekonomi Institut Pertanian Bogor.

Gomes, Faustino Cardoso. 2013. Manajemen sumber daya manusia. Yogyakarta: Andi Yogyakarta.

Mangkunegara, Anwar Prabu. 2011. Perilaku Dan Budaya Organisasi. Bandung: Refika Aditama.

Mangkunegara, Anwar Prabu, Manajemen Sumber Daya Manusia Perusahaan, Penerbit PT. Remaka Rosdakarya, Bandung, Tahun 2012 Halaman 164.

Nawawi, H. Handari, Manajemen Sumber Daya Mnausia, Penerbit Gajah Mada Universitas Press, Yogyakarta, Tahun 2011, Halaman 89.

Nuranda, Agung. 2012. Pengaruh Stres Kerja Terhadap Kinerja Karyawan PT. PLN (Persero) Cabang Makassar.Skripsi tidak diterbitkan. Makassar: Jurusan 
Manajemen Fakultas Ekonomi

Universitas Hasanudin. 
